\title{
Fórmulas de rotina: uma porta de entrada para padrões interacionais
}

\section{Eva Glenk**}

\begin{abstract}
In this paper we try to show that formulae give evidence of as well as initiate conventional patterns of interaction. These interactional patterns, shaped by a particular linguistic community, are not universal. Their knowledge is part of idiomatic competence. A bilingual semasiological and onomasiological dictionary can contribute not only to the acquisition of formulae but can also transmit knowledge of conventional patterns of interaction.
\end{abstract}

Keywords: Contrastive Phraseology and Lexicography: Portuguese-German; Formulae; Conventional interactional patterns.

Zusammenfassung: In diesem Beitrag soll gezeigt werden, dass Formeln Indizien für konventionelle Interaktionsmuster sind und diese umgekehrt auch initiieren. Diese von der jeweiligen Sprachgemeinschaft geprägten Interaktionsmuster sind nicht universell; ihre Kenntnis ist Teil der idiomatischen Kompetenz. Ein zweisprachiges semasiologischonomasiologisches Wörterbuch kann nicht nur zum Erwerb von Formeln beitragen sondern auch das Wissen über Interaktionsmuster vermitteln.

Stichwörter: Kontrastive Phraseologie und Lexikographie: Portugiesisch-Deutsch; Formeln; konventionelle Interaktionsmuster.

Resumo: Nesse trabalho, será mostrado que fórmulas dão evidência de padrões convencionais de interação e também os inicializam. Esses padrões de interação não são universais, mas são configurados por cada comunidade lingüística. Conhecê-los faz parte da competência idiomática. Um dicionário bilíngüe semasiológico e onomasiológico pode contribuir tanto para a aquisição de fórmulas, quanto transmitir o conhecimento de padrões de interação.

Palavras-chave: Fraseologia e lexicografia contrastiva: alemão-português; fórmulas; padrões convencionais de interação.

\section{A Fórmula}

O termo 'fórmula', conhecido e difundido na Lingüística em boa parte graças à obra Routine im Gespräch de COULMAS (1981), designa, segundo STEIN (2004), todas as cristalizações lingüísticas que mostram especial fixidez pragmática, sem por isso serem obrigatoriamente fraseologismos stricto sensu,

\footnotetext{
* Co-tradutora: Lúcia Zanetti; revisão: Masa Nomura

** Professora doutora do Departamento de Letras Modernas: Área de Alemão da Universidade de São Paulo. spoelten@usp.br
} 
ou seja, grupos de palavras com no mínimo duas palavras e no máximo a extensão de uma frase.

Fórmulas apresentam fixidez pragmática porque "são reproduzidas pelos interlocutores em determinadas situações comunicativas para levar a cabo determinadas tarefas comunicativas de modo rotineiro". (cf. STEIN 2004: 264).

Assim, o termo 'formulaico' engloba meios e estruturas pré-formadas que facilitam a produção de texto e garantem aos interlocutores uma ação lingüística adequada às normas comunicativas.

A formulaicidade é, portanto, um recurso lingüístico-comunicativo, adquirido através da experiência comunicativa, que dá conta de problemas recorrentes de comunicação e de formulação.

\subsection{Tipos de fórmulas}

Distingue-se entre fórmulas atreladas à situação e fórmulas nãoatreladas à situação, utilizadas na execução de atividades lingüísticas e de tarefas comunicativas recorrentes:

- Fórmulas de rotina: são atreladas à situação, mas amplamente independentes do contexto. Podem ser classificadas como fórmulas de polidez, de contato, agradecimento, cumprimento e despedida, fórmulas de conversação (Bitte mal herbören!; Atenção por favor!), fórmulas à mesa, fórmulas de repreensão e maldição (Verflixt und zugenäbt!;Que droga!) ou fórmulas de comentários: fórmulas de dúvida, rejeição, crítica, réplica e contrariedade (Tu, was du nicht lassen kannst!; Você que sabe), fórmulas de surpresa (Mir fehlen die Worte!; Estou pasma!), fórmulas de concordância (Das will ich meinen!; Sem dúvida!), fórmulas de conciliação, admoestação e motivação (Rubig Blut!; Deixa pra lá.).

- Fórmulas discursivas: não são atreladas à situação, mas são dependentes do contexto e podem ser utilizadas em diferentes níveis da execução da interação com diverso potencial funcional. Sua ocorrência pode ser percebida através da análise contextual. Exemplos desse tipo de fórmula são: ich meine, oder so, offen gesagt, weißt du, etc. (eu acho, falando sem rodeios, sabe etc.) (cf. ibid.) 
Fórmulas contribuem tanto para a comunicação oral quanto para a comunicação escrita.

O uso de fórmulas, por um lado, pode ter motivação social: aumenta a segurança de comportamento e simboliza a identidade social (função "chibolete"), facilitando ao mesmo tempo a produção de texto.

Por outro lado, as fórmulas podem assumir funções de organização discursiva em diálogos: na troca de turnos, na integração da produção e da recepção, na sinalização de familiaridade entre os interlocutores, no desenvolvimento livre do assunto, no cruzamento de situações, e outros.

\subsection{A fixidez das fórmulas na fala e sua evidência na mente}

As fórmulas são a 'ponta do iceberg' de toda formulaicidade da língua. Ao invés do termo 'formulaico', também é usual o termo 'convencional', como encontrado em TAGNIN (2005:15), que faz a distinção entre a convenção social e a convenção lingüística. Convenção social diz respeito, segundo a autora, ao saber, p.ex., de que é adequado pedir desculpas quando se pisa no pé de alguém. Como exemplo para a convenção lingüística, ela cita o conhecimento sobre a MANEIRA de se realizar verbalmente um pedido de desculpas. A formulaicidade, como Stein a define (ver acima), corresponde, assim, à convenção lingüística, que faz parte, por sua vez, da convenção social.

As fórmulas provavelmente são o que há de mais fixo na comunicação: determinadas situações requerem o uso de determinadas expressões lingüísticas. Isso vale tanto para o âmbito institucional, quanto para a maioria de todas as outras situações comunicativas, ainda que em menor ou maior grau. Temos como diferentes graus de fixidez:

- Um exemplo para o primeiro caso é a fórmula Bitte zurücktreten; Afastemse das portas, que é usada pelo controlador dos transportes públicos para direcionar as pessoas antes do fechamento das portas do metrô. Outro exemplo é a fórmula Nada mais havendo a tratar, encerrou-se a reunião e eu, $X Y$, lavrei esta ata, que é acrescentada ao final das atas de determinadas instituições.

- Um pouco menos fixa é uma fórmula como Guten Tag; Bom dia: quando encontramos um conhecido, é necessário cumprimentá-lo, se não quisermos infringir o código da polidez, entretanto, temos uma certa liberdade na escolha da fórmula. 
- O uso de uma fórmula como Herzlichen Glückwnnsch zum Geburtstag!; Feliz aniversário! é ainda menos fixo: ela pode ser substituída por fórmulas semelhantes ou mesmo por uma formulação relativamente livre. Seu uso também não é tão obrigatório como o das fórmulas supracitadas: os interlocutores podem escolher ignorar o aniversário de alguém, sem com isso serem taxados de extremamente mal-educados, esquivando-se assim da necessidade de manifestar-se verbalmente. Caso o interlocutor escolha parabenizar o outro pelo aniversário, ele precisará recorrer a padrões mais ou menos fixos (como já foi mostrado).

- No nível menos fixo/s/, do ponto de vista pragmático, dentre/d/as fórmulas encontra-se, por exemplo, uma fórmula de comentário como Ich glaub mich laust der Affe!; Macacos me mordam!. Essas fórmulas expressam uma forma de espanto bastante jovial. O espanto, a surpresa, no entanto, podem ser expressos de diferentes maneiras; além disso, não é necessário expressá-los.

$\mathrm{Na}$ língua materna, muitas das fórmulas são adquiridas e ensinadas ativamente: as crianças aprendem desde cedo a dizer por favor e obrigado, a cumprimentar de tal e tal maneira, a pedir desculpas, etc., o que contribui para pôr em evidência as fórmulas.

Mas se qualificamos as fórmulas como a 'ponta do iceberg' da convenção lingüística, isso se deve não somente ao fato de elas estarem muito presentes na mente dos falantes (alto grau de conscientização) ou de serem pragmaticamente fixas, mas, antes de mais nada, porque são indicadores de padrões convencionais de comportamento, que devem ser pensados como a base do iceberg de nossa metáfora. Trataremos desses padrões de comportamento convencionais ('Verbaltensmuster) e de seus respectivos padrões de interação mais adiante.

\subsection{O conceito de 'fórmula' em oposição a outras expressões fraseológicas}

Pode-se classificar as fórmulas - com exceção das fórmulas compostas por uma palavra - como fraseologismos stricto sensu. Elas foram denominadas "fraseologismos pragmáticos" por BURGER/BUHOFER/SIALM (1982); mais tarde, "fraseologismos comunicativos", e/ou "fórmulas de rotina", que englobam, segundo BURGER (2007) tanto as fórmulas atreladas à situação (p. 
ex.: Grüß Gott; Bom dia), quanto as fórmulas discursivas (p. ex.: ich meine; eu acho). $\mathrm{O}$ autor excluiu-as do grupo dos fraseologismos referenciais.

Contudo, as fórmulas de comentário (p. ex.: Das schlägt dem Fass den Boden aus!; Isso é o fim da picada!), segundo o autor, fazem parte das frases fixas ("Feste Phrasen") que pertencem ao grupo dos fraseologismos proposicionais, dentro do grande grupo dos referenciais (cf. BURGER 2007: 36-40).

Como STEIN (2004), WOTJAK (2005) também subdividiu as fórmulas em fórmulas de rotina (que incluem também as fórmulas de comentário) e fórmulas discursivas. Em sua classificação, as fórmulas discursivas fazem parte dos fraseologismos menores que uma sentença, ao lado das colocações (den Tisch abräumen; tomar sorvete), das locuções verbo-nominais (Verwendung finden; ), das locuções conjuntivas e prepositivas (mit Hilfe von; por meio de) e das expressões idiomáticas, também chamadas de fraseolexemas (expressões idiomáticas: jmdn durch den Kakao ziehen; tirar sarro de alguém e semi-idiomáticas: einen Streit vom Zaun brechen; falar abobrinha). As fórmulas de rotina, no entanto, são subordinadas ao grupo dos fraseologismos sentenciformes e textuais, juntamente com os provérbios (Lügen haben kurze Beine) e os textos formulaicos (p.ex.: notas de falecimento e receitas culinárias). Wotjak, ao contrário de Burger, não diferencia entre fraseologismos referenciais e nãoreferenciais. Para um panorama geral sobre a variedade terminológica, veja também LÜGER (1999: 29).

Para a diferenciação entre fórmulas de comentário ("frases fixas" para Burger; p. ex.: Schwamm drüber!; Isso são águas passadas!) e outros fraseologismos sentenciformes como os provérbios (p. ex.: Morgenstund hat Gold im Mund; Deus ajuda quem cedo madruga) e os lugares-comuns (p. ex.: Man lebt nur einmal; A vida é curta), DOBROVOLS'KIJ (1997:67) propõe os seguintes critérios:

(i) autonomia discursiva vs. inserção discursiva

(ii) apelo a uma "verdade universal" vs. referência a uma situação concreta

Enquanto os provérbios e os lugares comuns têm autonomia discursiva (funcionam como textos independentes), os "idiomatismos na função de enunciado" não são discursivamente autônomos. Essa dependência discursiva, segundo DOBROVOLS'KIJ (ib.), é freqüentemente marcada por diversos elementos dêiticos e anafóricos: 
Jetzt ist aber Sense!

Darauf kannst du Gift nehmen!

Isso é batata!

Provérbios e lugares comuns são textos fechados, cuja tarefa é veicular o modelo de mundo de uma determinada sociedade. Eles transmitem regras de comportamento e normas (cf. GLENK 2000) e apresentam freqüentemente estruturas típicas e determinados elementos formais como rima e aliteração:

Wo ein Wille ist, da ist auch ein Weg.

Mitgefangen, mitgehangen.

Bellende Hunde beißen nicht.;

Querer é poder.

A ocasião faz o ladrão.

Cão que ladra, não morde.

As fórmulas, por outro lado, referem-se a uma situação concreta; não encerram nenhuma "verdade universal".

No presente trabalho, limitaremos nossa discussão às fórmulas sentenciformes e atreladas à situação, ou seja, às fórmulas de rotina.

\section{As fórmulas, os padrões de interação e o dicionário bilíngüe}

Baseado em um catálogo de critérios, WOTJAK (2005) analisa em seu artigo "Routineformeln im Lernerwörterbuch" o tratamento dispensado às fórmulas por dicionários para aprendizes e dá sugestões para sua descrição lexicográfica monolíngüe.

Partindo da análise de dois dicionários para aprendizes, a autora defende dicionários de fórmulas de rotina independentes, mono e bilíngües, que combinem critérios semasiológicos e onomasiológicos e tenham espaço para inserções contextuais. Com isso, reforça a já histórica exigência da perspectiva onomasiológica em dicionários bilíngües de fórmulas de rotina (veja também HYVÄRINEN 2003, WIEGAND 2004).

Com base nas reflexões de WOTJAK sobre fórmulas de rotina em dicionários para aprendizes, levantaremos alguns problemas que aparecem na coleta de fórmulas atreladas à situação, e na sua descrição no dicionário bilíngüe. Em seguida, ilustraremos através da análise da fórmula de contato Desculpe qualquer coisa a necessidade de uma abordagem semasiológica e onomasiológica na dicionarização das fórmulas para permitir o acesso também aos padrões de interação subjacentes às fórmulas. 


\subsection{Levantamento das fórmulas atreladas à situação: o uso de corpora e as condições situacionais}

\subsection{1. $O$ uso de corpora}

A questão sobre o levantamento de dados é respondida na literatura atual de maneira unívoca pela exigência do uso de corpora. Embora os dicionários precedentes possam servir como ponto de partida para a busca das entradas, os corpora são indispensáveis por vários motivos. WELKER (2003) menciona o levantamento das diversas acepções de um lexema (no nosso caso, frasema) como um motivo importante para o uso de corpora. Para a nossa pesquisa, o uso de corpora é imprescindível também por outros motivos: somente o levantamento das fórmulas na respectiva situação comunicativa possibilita uma descrição fraseográfica adequada e é o primeiro passo para um procedimento onomasiológico.

Quando pensamos no par lingüístico alemão/português do Brasil, os corpora ainda são um desiderato. Embora alguns corpora de alemão online de boa qualidade já estejam à disposição do público (p.ex. O Cosmas do Institut für Deutsche Sprache, Mannheim), o mesmo não acontece com o português do Brasil. Segundo WeLKER, existem alguns corpora de português do Brasil, que, no entanto, não estão disponíveis em formato eletrônico. Do mesmo modo, faltam corpora paralelos (textos autênticos e suas respectivas traduções). Essa situação faz necessária a recorrência à rede para determinados tipos de pesquisa, utilizando-se ferramentas de busca como o Google.

Esse procedimento, porém, exige uma minuciosa filtragem manual dos dados para que se obtenham resultados de qualidade.

\subsubsection{Condiçães situacionais: Investigação da relação entre as fórmulas e os padrões de interação}

Encontramos em muitas obras a exigência de levar-se em consideração o contexto na descrição das fórmulas. Dois aspectos (pragmáticos) são de especial relevância. São eles, segundo STEIN (1995: 150), as condições situacionais, sob as quais uma determinada fórmula é usada, e a função que desempenha no discurso.

As fórmulas são "convencionalmente atreladas a um padrão de ação verbal pelo menos" (KÜHN 1984: 194), e com elas o interlocutor "realiza sempre os mesmos atos de fala" (STEIN 1995: 150). Por isso, a indicação de 
características situacionais, que determinam o usa da fórmula e tornam-no previsível, não só é possível como também recomendável em um dicionário.

Uma vez que a noção de que cada fórmula é atrelada a um padrão de interação pelo menos, é de grande importância para nossas reflexões, tentaremos relacioná-la com as seguintes teses:

a) Previsibilidade de determinados tipos de formulações em uma determinada situação comunicativa:

Em determinadas situações, para determinados tipos ações verbais, em determinados grupos sociais, etc., determinados tipos de formulações são convencionalizados; eles são esperados mutuamente pelo sujeito emissor e pelo receptor. (SANDIG 1978: 16).

b) Consciência dos falantes sobre a correlação de determinadas formulações convencionais (dos fraseologismos) e de determinados tipos de textos (que, por sua vez, são subordinados a determinadas situações comunicativas):

Os usuários da língua, tanto como produtores, quanto como receptores do texto, possuem a percepção intuitiva de que os fraseologismos são importantes características distintivas de tipos de texto, e, de que, com base nos mesmos, certos tipos de textos podem ser identificados. [...] Logo, isso indica que certos tipos de fraseologismos e certos tipos de textos estão correlacionados. (BURGER/ BUHOFER/ SIALM 1982: 109)

c) Sanções por inobservância dessa correlação entre formulações convencionais e determinadas situações comunicativas e/ou determinados tipos de texto:

Quem vai a um cabelereiro do subúrbio para cortar o cabelo e não consegue entrar - com um tipo de discurso razoavelmente técnico ou característico do grupo local - na conversa atual sobre futebol, oferecida de maneira solícita, poderá eventualmente perceber um distanciamento social no decorrer da conversa restante. Quem ainda inicia a sua palestra ou sua aula acadêmica com o tradicional Meine Damen und Herren (Senhoras e Senhores), pode vir a sofrer a influência disso sobre sua imagem perante os ouvintes [...]. (PolenZ 1985: 224-225)

d) A indicação e iniciação de um esquema de ação complexo através de formulações convencionais:

Determinadas situações comunicativas exigem determinados comportamentos lingüísticos, que, por sua vez, levam à escolha de determinadas formulações. FEILKE (1994) procurou demonstrar, através de um experimento, que determinadas formulações podem indicar e inicializar 
um determinado comportamento lingüístico em uma determinada situação comunicativa. Para o experimento, ele apresentou fragmentos de um texto contendo fraseologismos a voluntários, juntamente com a tarefa de anotar espontaneamente idéias surgidas sobre o conteúdo do texto e suposições sobre o contexto comunicativo. Como resultado, ele obteve (as) reconstituições do texto, que se aproximaram consideravelmente do texto original. Essa mediação entre "a(s) estrutura(s) textual(ais) manifesta(s) e as estruturas do conhecimento de mundo" no processo da formação da coerência textual é produzida através da "competência idiomática" do falante/ouvinte. (FeILKE 1994: 213). Trata-se do conhecimento de que os signos lingǘsticos são marcados idiomaticamente pela sua 'mais-valia' semântica, agregada através do uso (cf. também BÜHLER 1934/1982 apud FEILKE 1994).

A marcação idiomática é identificável em todos os lugares, onde os signos lingüísticos em uso e/ou através de seu uso recebem, conforme Bühler, $>$ um encargo sematológico $<$ e esse $>$ encargo $<$ de mais-valia semântica ou também pragmática é incorporado à competência, ou seja, torna-se convencional e assim faz parte do conhecimento lingüístico que pode ser pressuposto dentro de uma comunidade lingüística. (FEILKE 1994:235)

A marcação idiomática dos signos lingüísticos evidentemente não ocorre de maneira igual com todos os signos. O êxito do experimento supracitado dependeu essencialmente da escolha cuidadosa dos signos língüísticos, que deveriam possibilitar a reconstrução de um determinado texto. Assim, os voluntários do experimento conseguiram, como previsto, concluir a partir da fórmula Ich erbebe mein Glas que o seu co-texto era uma ocasião solene e o seu contexto um discurso. A reconstrução do texto não teria sido tão simples, se tivesse sido feita a partir de signos lingüísticos nãofraseológicos. Uma palavra como Radieschen (rabanete), p.ex., possibilitaria, segundo Bühler, apesar de sua 'aura' ('Sphärengeruch) a associação de muitos diferentes cenários (p.ex. cozinha, jardim, feira). Para a indicação e iniciação de um concreto e complexo padrão de ação é necessário um ato de fala convencional independente, verbalizado por meio de uma fórmula.

Para o trabalho lexicológico com fórmulas pode-se depreender das considerações anteriores que o contexto, no qual cada fórmula ocorre, deve ser submetido a uma análise usando critérios da análise da conversação e da lingüística do texto quando o intuito for compreender a fórmula como um todo. 


\subsection{A busca por equivalentes}

Quem utiliza um dicionário bilíngüe, procura na maioria dos casos ou a) os equivalentes na L1 para determinados lexemas na L2 ou b) os equivalentes na L2 para determinados lexemas na L1, com um dos seguintes objetivos:

- A compreensão simples, superficial;

- A compreensão mais profunda;

- Tradução da L1 para L2;

- Tradução da L2 para L1;

- Produção 'livre' na L2

(cf. WELKER 2003: 21)

Partindo-se do pressuposto de que os usuários medem a qualidade de um dicionário levando em consideração "até que ponto o lexicógrafo conseguiu estabelecer a equivalência entre as unidades lexicais da língua de partida e da língua de chegada" (KROMANN/RIIBER/ROSBACH 1984), então evidentemente surgem as seguintes questões: o que se entende por equivalência, quais os tipos de equivalentes e como são encontrados pelo lexicógrafo.

\subsection{1. $O$ conceito de equivalência:}

Fala-se de equivalência quando um lexema/frasema/textema de uma língua pode ser substituído por um lexema/frasema/textema de outra língua, para designar o mesmo conceito ou conceitos muito semelhantes e/ou desempenhar a mesma função ou uma função semelhante.

O número de autores, que se ocupam de diferentes tipos de equivalentes, é grande. Encontram-se na literatura as mais diversas diferenciações de equivalência, desde uma subdivisão mínima entre equivalência total, equivalência parcial ou incompleta e equivalência nula até uma classificação que distingue 13 tipos diferentes de equivalência.

O conceito da 'equivalência do uso da palavra', que SCHOLZESTUBENRECHT (1995) subdivide em equivalência semântica, estilística, pragmática, terminológica, diacrônica, contextual, sintático-gramatical, metafórica, etimológica, morfológica, de freqüência, sonoro-rítmica e diatópica, certamente representa uma das noções mais completas de equivalência. Esse conceito é completado pelas noções de divergência, convergência e 'multivergência' (divergência: um lexema da L1 corresponde a 
dois ou mais lexemas da L2; convergência: um lexema da L2 corresponde a dois ou mais lexemas da L1; 'multivergência': a ocorrência de convergência e divergência simultaneamente), descritas por HAUSMANN (1994).

Esses dois grupos de conceitos (a equivalência do uso da palavra e o trio divergência, convergência e 'multivergência'), que descrevem uma relação interlingüística, correspondem aos conceitos intralingüísticos de sinonímia e polissemia, respectivamente.

Para verificar a sinonímia entre duas palavras, recorremos ao clássico teste operacional, em que duas palavras são qualificadas como sinônimas, "quando posso substituir uma pela outra em todos os casos (substituição), sem modificar o significado do enunciado como um todo." (Linke/Nussbaumer/PorTMAnN 2004: 169s). É evidente que isso torna quase impossível uma sinonímia perfeita entre palavras. Diferenças regionais, de registro, socioletais, estilísticas, referentes ao tipo de texto e à atitude do falante, tanto quanto as restrições de colocação (a "conotação da palavra") diferenciam os significados de palavras aparentemente sinônimas, como mostram os exemplos extraídos parcialmente da obra citada:

As palavras consideradas sinônimas Baby/Sängling (assim como neném/bebê em português) não podem ser substituídas umas pelas outras. Sängling é a palavra mais técnica, sendo apropriada no âmbito hospitalar, mas não em um estabelecimento comercial, p.ex. Assim,

Wo ist hier die Säuglings-Abteilung?

evoca o ambiente hospitalar, ao passo que

Wo ist hier die Baby-Abteilung?

Remete a um estabelecimento comercial.

Existem também claras restrições colocacionais. Podemos dizer de uma mulher grávida:

Sie bekommt ein Baby.

Mas não:

Sie bekommt einen Säugling.

Um exemplo para restrições estilísticas e restrições referentes ao tipo de texto e à atitude do falante podemos observar no trio de palavras entschlafen/ 
sterben/ kerepieren (falecer/ morrer/ bater as botas); restrições regionais em Tomate/ Paradeiser (mandiocal macaxeira) e assim por diante.

Encontrar intralingüisticamente sinonímias 'perfeitas' é quase tão difícil quanto encontrar equivalentes totais interlingüisticamente. Conseqüentemente, o lexicógrafo e o fraseógrafo se deparam com um grande número de equivalentes parciais, cujas diferenças de significado e de uso devem ser descritas e tornadas acessíveis ao usuário do dicionário.

Antes de partirmos para a questão da descrição dos equivalentes, devemos ainda tratar da questão sobre como encontrar os equivalentes. Segundo WELKER (op.cit.), os lexicógrafos têm as seguintes opções: a) basearse em dicionários existentes; b) traduzir; c) consultar falantes bilíngües; d) proceder de maneira científica, comparando a análise dos sememas de ambos os lexemas entre si. GLENK (2003: 207) sugere um método que vai além do proposto no item d): ele permite também a descrição do uso do fraseologismo e dos padrões interacionais subjacentes:

... os fraseologismos [...] são coletados, analisados em seus contextos, seus frames são descritos; através da tradução tenta-se encontrar seu equivalente na língua de chegada [...] que, por sua vez, são descritos e depois comparados com os fraseologismos da língua de partida.

\subsubsection{A equivalência de padrões de interação}

Os esforços para encontrar equivalentes partem freqüentemente do pressuposto tácito de que existem conceitos universais sobre pelo menos três objetos:

1. sobre os objetos do mundo externo que fornecem o denotatum; 2. sobre o tipo das relações mundo exterior - homem; 3. sobre o tipo de relações que pode haver entre homem - homem. (cf. CHEON 1998).

Não concordamos com esta idéia; os conceitos realmente universais talvez sejam mais raros do que se imagina. Parece-nos mais adequado falar em esquemas pré-conceituais, como postulados por LAKOFF (1987) e JOHNSON (1987): Container, Part-Whole, Link, Center-Periphery, Source-Path-Goal, Up-Down, Front-Back.

Por isso, pode se pressupor que não só muitas palavras, mas também muitos conceitos tenham apenas equivalentes parciais na comunidade da língua de chegada. 
O que vale para os conceitos vale mais ainda para os padrões de ação, de comportamento e de interação, muito mais complexos que os conceitos.

A falsamente postulada universalidade dos padrões de interação pode não somente levar a problemas de comunicação e a perturbações nas relações individuais, mas também a problemas interculturais de natureza social. Esse é um dos motivos pelo qual a equivalência comunicativa de expressões lingüísticas merece atenção especial na produção de um dicionário de língua estrangeira.

Os padrões interacionais - semelhante às expressões fraseológicas podem apresentar equivalência total, parcial ou nula na língua de chegada; portanto, falaremos em equivalência comunicativa perfeita, equivalência comunicativa parcial ou equivalência comunicativa nula.

Equivalência comunicativa perfeita: muito rara e encontrada somente entre padrões de interação em comunidades lingüísticas de níveis sócioeconômico, cultural e geográfico muito semelhantes.

Equivalência comunicativa parcial: a maioria dos padrões de interação de duas comunidades lingüísticas deve apresentar uma certa correspondência, indo de "muito grande" a "muito pequena".

Equivalência comunicativa nula: prevista entre comunidades lingüísticas com níveis sócio-econômico, cultural ou geográfico muito diferentes.

Para efeito de ilustração da equivalência comunicativa parcial (ou seja, da equivalência parcial de padrões de interação), citaremos aqui os resultados de pesquisas do âmbito da análise da conversação, que implicam parcialmente no uso de fórmulas.

\section{Padrão interacional AGRADECER:}

Kerbrat-Orecchioni chama a atenção para o fato de que o comportamento de agradecimento pode ser muito diferente em culturas distintas: tanto a freqüência quanto as situações em que se agradece, variam de cultura para cultura:

Enquanto que na França agradece-se ao vendedor pela compra da mercadoria, não se age dessa maneira em muitos países asiáticos, já que a partir do momento em que o cliente paga, ele não tem mais a obrigação de exprimir reconhecimento particular. 
Ao trocarem objetos ou presentes entre si, pessoas proximamente relacionadas (amigos ou membros da família) não agradecem, ou melhor: não lhes é permitido agradecer: é assim na Índia, Coréia, Japão, Zaire etc., completamente diferente da maioria dos países ocidentais.

Mas também as maneiras de expressar agradecimento podem ser surpreendentemente diferentes: os japoneses usam fórmulas que na verdade são pedidos de desculpas, para agradecer outras pessoas (quem recebe um presente, sente-se na posição de devedor, logo, culpado).

$\mathrm{Na}$ verdade, a problemática nessas diferenças é que "os membros das diferentes culturas [....] crêem que as normas que lhes foram inculcadas desde a mais tenra idade são universais.” (KERBRAT-ORECCHIONI 2006: 138-9)

Essas "disfunções" podem provocar "situações desconfortáveis" e assim levar a "graves traumas" e "feridas culturais". A autora levanta a suspeita de que "os reflexos xenófobos" [...] pudessem ser provenientes "de um grave desconhecimento da diversidade cultural das normas interacionais". (ib. 139-140)

Padrão interacional ARGUMENTAR:

Partindo de análises do estilo conversacional de diferentes grupos étnicos de língua materna inglês, que convivem na América do Norte, e dos problemas de comunicação observados em conversas do dia-a-dia entre participantes desses grupos, GUMPERZ (1982) chega à conclusão de que as diferentes estratégias retóricas desses grupos (indianos, norte-americanos, britânicos) levam a problemas comunicativos. $\mathrm{O}$ autor observou, p.ex., uma conversa, em que um estudante indiano foi interrompido pelos outros interlocutores, antes que ele pudesse expressar sua opinião. Concluiu que o problema surgiu porque o estudante deu - como introdução à expressão de sua opinião - um resumo detalhado das opiniões até então emitidas pelos outros. Esse procedimento está em acordo com o estilo de discussão indiano, mas não com o dos norte-americanos.

> Padrão interacional EXPRESSAR DISSENSÃO:

O seguinte exemplo trata dos estilos de discussão de mulheres e homens alemães e brasileiros. A pesquisa realizada por MEIRELES (2003: 229) mostrou que

[...] mulheres alemãs usam expressões como ich glaube/ finde/ denke [...] quatro vezes mais do que os homens alemães, enquanto a análise de 
discussões brasileiras não mostraram diferenças significantes a esse respeito. [...] a busca de consenso e harmonia na interação é típica para a linguagem feminina em culturas nas quais existem estilos conversacionais diferentes para mulheres e homens.

A autora deduz disso que homens alemães utilizam um estilo 'mais agressivo, mais centrado no falante', enquanto tanto as mulheres quanto os homens brasileiros privilegiam geralmente o estilo argumentativo centrado no ouvinte.

Baseado na experiência intercultural própria poderíamos acrescentar uma longa lista de padrões interacionais, ou seja, de scripts, que diferem nas comunidades lingüísticas alemã e brasileira. Aqui apenas um esboço de alguns scripts diferentes em alemão e em português do Brasil, inicializados em determinadas situações (cf. GLENK 2006):

Tratamento: $D u /$ Sie vs. você/ Senhor(a): enquanto a escolha entre $D u$ e Sie é norteada sobretudo pelos parâmetros proximidade/ distância, a escolha entre você e Senhor(a) é determinada sobretudo pelo 'respeito' (diante de pessoas mais idosas, em posição hierárquica mais alta, mais influentes etc.).

Emitir opinião: Quantas vezes um estudante universitário, p.ex., precisa tomar a palavra em uma discussão? Com que insistência precisa defender sua opinião?

Conversar: Em que situações públicas é necessário que estranhos que aguardam ou viajam juntos façam contato verbal?

Estilo direto/ indireto: Quanto tempo é necessário conversar ao telefone sobre as famílias/ interesses amenos dos interlocutores antes de tematizar o objetivo da chamada?

Como se transmitem notícias tristes?

Fazer valer os próprios desejos: Quais tipos de pedidos têm maior sucesso em uma comunidade lingüística: diretos ou indiretos? Formulações favoráveis ao image do ouvinte ou pedidos que enfatizam a necessidade objetiva do objeto desejado?

A correlação entre padrões de interação e fórmulas possibilita a captação onomasiológica das fórmulas, isto é, seu levantamento e sua descrição a partir dos padrões de interação aos quais são atreladas. 


\subsection{O dicionário ideal: fórmulas e padrões interacionais representados através de procedimentos semasiológicos e onomasiológicos}

Um dicionário fraseológico polifuncional elaborado através de procedimentos semasiológicos tanto quanto onomasiológicos permite ao usuário não somente o acesso bi-direcional às fórmulas, mas lhe dá acesso também aos padrões interacionais subjacentes a essas, além de fornecer-lhe o equivalente comunicativo na outra língua.

Esse dicionário lista na parte semasiológica as fórmulas em ordem alfabética; na parte onomasiológica, os padrões interacionais (também scripts) são listados e relacionados com as fórmulas através de referências.

Tanto a parte semasiológica quanto a onomasiológica devem apresentar a subdivisão em uma parte L1 e uma parte L2.

$\mathrm{Na}$ parte semasiológica, as fórmulas servem de entradas. $\mathrm{Na}$ microestrutura do verbete, seu significado e suas condições de uso são indicados de maneira metalingüística e através de um exemplo. Além disso, há a referência a um script ao qual pertencem.

$\mathrm{Na}$ parte onomasiológica, os scripts servem de entradas. São descritos e trazem a referência a uma fórmula, através da qual podem ser realizados.

Partindo-se do pressuposto de que existem apenas poucos scripts universais, os scripts de ambas as línguas precisam ser listados e essas listas confrontadas quanto às suas equivalências. Dessa maneira haverá para cada script da L1 um/ nenhum ou vários scripts da L2, e vice-versa.

Isso significa para a utilização do dicionário que o usuário que quer compreender, usar ou traduzir p.ex. a fórmula Desculpe qualquer coisa!, encontrará na microestrutura do verbete primeiras informações junto com a referência ao(s) $\operatorname{script}(\mathrm{s})$ brasileiro(s) a que pertence. Procurando esse script, encontrará uma descrição completa com a indicação paradigmática de algumas possíveis realizações, além de seu equivalente alemão.

\section{Análise da fórmula Desculpe qualquer coisa como representante dos padrões interacionais ENCERRAR O CONTATO e/ou GERENCIAR UMA SITUAÇÃO DE POSSÍVEL CONFLITO}

A fórmula de contato Desculpe qualquer coisa é, segundo a intuição do falante, usada predominantemente na comunicação oral. Nossa pesquisa mostrou, no entanto, que está presente também na comunicação escrita. 
Trata-se de uma fórmula que não tem um equivalente total em alemão. Fórmulas que se aproximam e que poderiam ser usadas em alguns contextos como equivalentes, são, p.ex.: Entschuldigen Sie die Umstände ou Nichts für ungut!.

O dicionário HouAIss (2001) lista no verbete para desculpar no item 7 a seguinte acepção:

pedir desculpa(s) (<desculpa-se por qualquer coisa $>$ ) (sinal de círculo) USO como sinal de polidez, emprega-se para pedir desculpa por algo possivelmente insatisfatório, ou por uma coisa que pode aborrecer, como meio de atenuá-la (p.ex., queira d. a falta de comodidade; desculpe a insistência; desculpe, não o ouvi bem>)

A fórmula tem quatro variantes:

desculpe/ a / em qualquer coisa

respectivamente

desculpe / a/ em por qualquer coisa

$\mathrm{e}$

desculpe/a/ em alguma coisa

respectivamente

desculpe/a/ em por alguma coisa

O significado de qualquer coisa e alguma coisa encontramos outra vez no HOUAISS (op.cit.):

Qualquer coisa: qualquer: designativo de pessoa, objeto, lugar ou tempo 1. indeterminado (um, uma, algum, alguma); 2. indiscriminado, equivalendo a este ou aquele, esta ou aquela, um ou outro, uma ou outra; 3. todo, toda, cada; [...]; cada um.

Alguma coisa: algum: para indicar de modo indeterminado qualquer dos indivíduos da espécie referida pelo substantivo ou pronome a que está ligado; certo número de algo; um tanto; nem muito, nem pouco.

O verbo desculpar é usado no imperativo e pode aparecer nas seguintes pessoas do imperativo:

- Na $3^{a}$ pessoa do singular, que corresponde às formas de tratamento você ou Senhor/a, aos tratamentos informal e formal, portanto;

- Na $2^{a}$ pessoa do singular, que corresponde à forma de tratamento $t u$. Em geral, com (a) exceção de algumas regiões brasileiras onde o th (tanto com o verbo na $2^{\mathrm{a}}$ pessoa quanto na $3^{\mathrm{a}}$ pessoa do singular) ainda é usado, esse imperativo é considerado uma variante coloquial do imperativo da $3^{a}$ pessoa do singular; 
- $\mathrm{Na} 3^{a}$ pessoa do plural, que corresponde às formas de tratamento vocês e Senhores/as, aos tratamentos informal e formal, portanto.

Para poder analisar a fórmula em uso, buscamo-na na web com a ferramenta de busca Google. Todos os levantamentos aqui mencionados foram feitos em abril de 2007. Em seguida, um quadro de todas as ocorrências :

\section{Variante:}

Desculpa qualquer coisa

Desculpem qualquer coisa

Desculpe por qualquer coisa

Desculpa alguma coisa

Desculpa por qualquer coisa

Desculpa por alguma coisa

Desculpe qualquer coisa

Desculpe por alguma coisa

Desculpem por qualquer coisa

Desculpem alguma coisa

Desculpe alguma coisa

Desculpe-me por qualquer coisa

Desculpem por alguma coisa

Desculpem-me qualquer coisa

Desculpe-me qualquer coisa

Desculpe-me alguma coisa
Número de ocorrências:

3670

1170

810

804

691

517

504

494

284

224

66

37

10

10

9

3

O alto grau de coloquialidade no uso da fórmula desculpe qualquer coisa e de suas variantes no texto escrito mostra-se através do fato de que a grande maioria das ocorrências do imperativo do singular prefere a conjugação em “a": há 5682 ocorrências de desculpa, mas apenas 1874 de desculpe.

A variante da fórmula com qualquer coisa é muito mais freqüente do que a variante com alguma coisa: há 7129 ocorrências de desculpe/a/ em qualquer coisa, mas apenas 2095 de desculpe/ a/ em alguma coisa.

Mais raras são as variantes desculpe/a/em por qualquer coisa ou por alguma coisa. As duas variantes mais freqüentes apresentam a valência desculpar + objeto direto.

As variantes mais raras apresentam a valência desculpar + por + substantivo (portanto, um objeto preposicionado). 
Muito raramente o verbo ocorre na sua forma reflexiva (desculpe/em-me: 59 vezes); por isso, desconsideramo-lo em nossa análise.

\section{Comparação com fórmulas similares:}

Para dimensionar os números, comparamos o número de ocorrências da fórmula desculpe qualquer coisa no Google da rede brasileira com os da fórmula (também brasileira) Desculpe o incômodo e de seu equivalente alemão Entscbuldigen Sie die Umstände:

Enquanto a fórmula Desculpe qualquer coisa com todas as suas variantes ocorre 9224 vezes, a fórmula Desculpe o incômodo ocorre - somente nessa variante - já 9380 vezes. Isso significa que essa fórmula ocorre em apenas uma variante mais freqüentemente do que Desculpe qualquer coisa em todas as suas variantes. Entschuldigen Sie (bitte) die Umstände é usada na rede alemã apenas 1965 vezes.

O quadro das ocorrências da fórmula Entschuldigen Sie die Umstände:

Variante:

Entschuldigen Sie die Umstände

Entschuldigt die Umstände

Entschuldigen Sie bitte die Umstände

Entschuldige die Umstände

Entschuldigt bitte die Umstände

Entscbuldige bitte die Umstände
Número de ocorrências:

265

131

101

10

Possíveis, porém muito raras (apenas 3 a 10 ocorrências cada) são as variantes com verzeiben no lugar de entschuldigen.

Esses números mostram que Desculpe qualquer coisa é uma fórmula usual, porém não tão freqüente quanto a fórmula mais específica desculpe o incômodo. O fato de ser menos usada em textos escritos extraídos da internet, do que outras fórmulas similares, não permite, no entanto, que se tire conclusões sobre sua freqüência em geral, já que não dispomos de dados provenientes da comunicação oral.

Nossa hipótese é que Desculpe qualquer coisa é uma fórmula típica da comunicação oral e, portanto, não tão presente na comunicação escrita como outras fórmulas similares. 
Submetemos 22 ocorrências da variante Desculpe qualquer coisa em contexto a uma análise detalhada. Para a análise utilizamos parâmetros extraídos dos modelos analíticos de CHEON (1998) e KonERding (1993), acrescidos de outros como, p.ex. o parâmetro "tipo de texto". Reunimos os resultados no seguinte quadro:

\section{a) Tipo de texto:}

E-Mails da venda online

Grupos de discussão (informática, matemática, jogos, grupo de estudos, e outros)

Cartas de leitores (emissora de rádio, revista, jornal)

Conselhos (jornal, revista)

Relato de uso oral da fórmula

\section{b) Fase do texto em que a fórmula é usada:}

Ocorre ANTES dos seguintes trechos do texto:

No fim do texto, imediatamente antes da assinatura

Quase no final, imediatamente antes de fórmulas como:

Grato pela atenção

Agradeço desde já qualquer tipo de ajuda. Aguardando sua resposta.

Sem problemas.

Qualquer dívida basta entrar em contato.

Raramente: em outro lugar

Ocorre APÓS os seguintes trechos do texto:

Pergunta

Solicitação de explicação

Solicitação de confirmação

Pedido de ajuda

Pergunta para esclarecimento de incompreensão

Conselho

Explicação dada 


\section{Opinião emitida}

Discussão anterior

\section{c) Razões para o pedido de desculpas:}

As razões aqui listadas que motivaram o pedido de desculpas, abrangem desde casos de reconhecimento de culpa intencional (raramente), passando por casos de reconhecimento de culpa não-intencional até casos de culpa hipotética ou a ausência de culpa. Em todos os casos, ocorre uma ameaça ou à face positiva do ouvinte ou do falante (no caso de crítica) ou à face negativa do ouvinte (em caso de pedido):

Crítica anterior (agressão) sofrida pelo ouvinte

Queixa anterior do ouvinte, explicação do falante

Possível mal-entendido, presumido pelo falante

Emissão de opinião do falante

Conselho / instrução anterior dada pelo falante

Performance possivelmente pobre do falante

Recusa/ cancelamento feito pelo falante

Pedido de conselho/ instrução/ ajuda, emitido pelo falante

Agradecimento do falante pelo conselho/ instrução/ ajuda obtida do ouvinte Sem razão

\section{d) Motivo para o uso da fórmula/ perlocução:}

Manter um bom relacionamento

\section{e) Interactantes:}

Em geral, não se conhecem pessoalmente; pouca familiaridade; diversas relações hierárquicas e institucionais; neutro quanto às emoções; raramente: pesar. Estilo: neutro, coloquial.

f) Ato de fala: expressivo: $O$ falante pretende convencer o ouvinte de sua estimação, e de seu desejo de manter o bom relacionamento recém iniciado. Falante reconhece a própria falibilidade. Fortemente esvaziado semanticamente. Ritualizado. 
g) Tipo de ação: Encerrar contato. Encontra um paralelo distante no âmbito ritual-religioso: a confissão obrigatória de culpa no início da missa católica: faz parte da condição humana nunca estar totalmente livre de culpa. O falante reconhece humildemente sua condição humana como pecador.

Podemos reduzir o significado de Desculpe qualquer coisa (no texto escrito) a duas acepções :

1. expressão (geralmente formal) do lamento de uma situação com carga negativa para o ouvinte, causada pelo falante. Essa situação pode ter maior ou menor carga negativa. Maior carga negativa: o falante disse/ fez algo que ofendeu/ poderia ofender o ouvinte; carga negativa menor: o falante pediu algo que pode causar/ causou inconvenientes ao ouvinte; menor carga negativa: o falante disse/ fez algo que deixou o ouvinte insatisfeito. 2. expressão do desejo de manter a relação 'sem ruídos', com o reconhecimento concomitante da possibilidade de uma perturbação causada pela falibilidade do falante.

Mesmo que um dicionário oferecesse todas essas informações, e indicasse possíveis equivalentes parciais para ela (já que não existe nenhum equivalente total), ainda não preencheria todas as necessidades do aprendiz/ usuário de língua estrangeira. No momento da produção em, ou tradução para o alemão, no entanto, surgem - dependendo da situação comunicativa - os problemas para o usuário, pois ele pode se deparar essencialmente com dois tipos de situações que exigem o acionamento de dois padrões interacionais distintos.

Um tipo de situação requer o acionamento do padrão GERENCIAR UMA SITUAÇÃO DE POSSÍVEL CONFLITO; o outro exige o acionamento do padrão ENCERRAR O CONTATO.

Quando o padrão interacional para GERENCIAR UMA SITUAÇÃO DE POSSÍVEL CONFLITO é acionado, há, nesse caso específico, equivalência comunicativa parcial entre o português do Brasil e o alemão, e fórmulas como Entschuldigen Sie bitte die Umstände! ou Nichts für Ungut! ou outro tipo de desculpa seriam - pelo menos à primeira vista - tão adequados em alemão quanto a fórmula Desculpe qualquer coisa em português.

Mas quando o padrão ENCERRAR O CONTATO é ativado, não se usaria nenhum dos equivalentes parciais sugeridos. Esse uso da fórmula ocorre mais freqüentemente na comunicação oral e, embora esteja pouco presente no meio urbano, ainda pode ser ouvida com certa freqüência pelos 
interiores do Brasil, como atestam tanto relatos em nosso corpus, quanto a própria vivência. Geralmente usada no fim de uma visita pelo visitante ou pelo anfitrião, ela é sinal de uma polidez que está caindo em desuso, como atesta o seguinte comentário mordaz e um tanto míope (a que 'escalões superiores da sociedade’ ele se refere?) de Carlos Heitor CONY (2004):

A expressão, que parece delicada ("desculpe qualquer coisa"), é quase exclusividade dos simples, das donas-de-casa que recebem visita e pedem desculpa antecipada por qualquer coisa. Caiu de moda nos escalões superiores da sociedade.

Nesse caso, os equivalentes alemães não cabem. Para ENCERRAR O CONTATO dir-se-ia em alemão algo inteiramente diferente de Nichts für Ungut!; talvez algo como Es war so schön, dass Sie hier waren! ou Ich hoffe, wir haben Sie nicht zu lange aufgehalten. Ou simplesmente nada.

Esse fato explica também por que a descrição semasiológica das fórmulas não consegue suprir todas as necessidades dos usuários dos dicionários, mas precisa ser complementada pela perspectiva onomasiológica. Somente dessa maneira, os padrões de interação tornam-se acessíveis aos usuários.

\section{Conclusão:}

Vimos que as fórmulas são o pars-pro-toto, a ponta do iceberg dos padrões de interação. O seu uso é esperado em determinadas situações comunicativas ou tipos de texto e sua omissão ou seu uso inadequado são sancionados. Mas conhecer as fórmulas ainda não garante uma comunicação adequada na língua estrangeira; já que os padrões de interação são tão pouco universais quanto sua expressão lingüística; eles também precisam ser aprendidos. Não somente o conhecimento fraseológico mas também o conhecimento dos padrões de interação subjacentes são parte integrante da competência idiomática, que aprendizes de uma língua estrangeira procuram adquirir. Um dicionário com características semasiológicas e onomasiológicas pode contribuir para a aquisição dessa competência tão importante na comunicação intercultural. 


\section{Referências bibliográficas:}

Burger, H. Phraseologie. Eine Einführung am Beispiel des Deutschen. Berlin, 2007..

Burger, H./ Buhofer, A. Sialm, A. Handbuch der Phraseologie. Berlin/ New York 1982.

CHEON, Mi-Ae. Zur Konzeption eines phraseologischen Wörterbuchs für den Fremdsprachler. Am Beispiel Deutsch-Koreanisch. Tübingen, Max Niemeyer, 1998.

Cony, C.H. "Filhos e livros". In: Folha de S. Paulo. São Paulo, 9/5/2004, www.folha.uol.com.br/ (02/05/2007)

Coulmas, F. Routine im Gespräch. Zur pragmatischen Fundierung der Idiomatik. Wiesbaden, 1981.

FEILKE, H. Common sense-Kompeten₹. Überlegungen zu einer Theorie "sympathischen" und "natürlichen" Meinens und Verstehens. Frankfurt a.M., 1994.

GLENK, E. Die Funktion der Sprichwörter im Text. Wien, Edition Praesens, 2000.

GLENK, E. "Brasilianisch-portugiesische und deutsche Phraseologismen im Kontrast: Beschreibungsverfahren und Äquivalenzsuche." In: Pandaemonium Germanicum 7, São Paulo/USP 2003, 191-214.

GLENK, E. "Die Vermittlung kultureller Skripts an Fremdsprachenlerner und -benutzer“. In: Akten des XII. ALEG-Kongresses. Havanna und Leipzig, 2006.

GuMPERZ, J. Discourse strategies. Cambridge, 1982.

Hausmann, F.J. „Typologie du dictionnaire général bilingue.“ In: FIGGE, U. (Hg.). Portugiesische und portugiesisch-deutsche Lexikographie. Tübingen, Niemeyer, 1994, 11-33.

HouAiss, A. Dicionário Houaiss da língua portuguesa. Rio de Janeiro, 2001.

HYväRINEN, I. „Der verbale Valenzträger.“ In: ÁGEL/ EICHINGER/ EROMS/ Hellwig et al. (eds.): Dependenz und Valenz. Ein internationales Handbuch der zeitgenössischen Forschung. Bd. 1 Berlin, 2003, 738-149.

Johnson, M. The Body in the Mind. Chicago, 1987.

Kerbrat-Orecchioni, C. Análise da conversação. Princípios e métodos. São Paulo, 2006.

KONERDing, K.-P. Frames und lexikalisches Bedeutungswissen. Tübingen, Niemeyer, 1993. 
KromanN, H.P./ RIIBER, T./ ROSBACH, P. „Überlegungen zu Grundfragen der zweisprachigen Lexikografie.“ In: Germanistische Linguistik 3-6, 1984, $59-238$.

KÜHN, P. (1984): „Pragmatische und lexikographische Beschreibung phraseologischer Einheiten." In: WIEGAND, H. (ed.): Studien zur neubochdeutschen Lexikographie IV. Hildesheim, Zürich, New York, 1984, 175-235.

LAKoff, G. (1987): Woman, Fire and Dangerous Things. What Categories Reveal about the Mind. Chicago, 1987.

Linke, A./ Nussbaumer, M. /Portmann, P. Studienbuch Linguistik. Tübingen, 2004.

LÜGER, H.-H. Satrwertige Phraseologismen. Wien, Edition Praesens, 1999.

MeIRELES, S. "Dissens und Höflichkeit - deutscher Diskussionsstil aus einer fremden Perspektive." In: Pandaemonium Germanicum 7, São Paulo/USP 2003, 215-232.

PolenZ, P.v.: Deutsche Satrsemantik. Berlin/New York, 1985.

SANDIG, B. Stilistik der deutschen Sprache. Berlin/New York, 1986.

SCHOLZE-STUBENRECHT, W. „Äquivalenzprobleme im zweisprachigen Wörterbuch.“ In: Germanistische Linguistik, 127-128, 1995, 1-16.

STEIN, St. Formelhafte Sprache: Untersuchungen zu ibren pragmatischen und kognitiven Funktionen im gegenwärtigen Deutsch. Frankfurt/M.; Berlin, Bern u.a., 1995.

STEIN, St. "Formelhaftigkeit und Routinen in mündlicher Kommunikation." In: STEYER, K. (ed.). Verbindungen mebr oder weniger fest. Jabrbuch IDS 2003. Berlin, 2004.

TAGnIN, S. O jeito que a gente dir. Expressões convencionais e idiomáticas. São Paulo, 2005.

WELKER, H.A. Zweisprachige Lexikographie: Vorschläge für deutsch-portugiesische Verbwörterbücher. München, 2003.

WIEGAND, H.E. „Lexikographisch-historische Einführung. “ In: DORNSEIFF, F.(ed.): Der deutsche Wortschatz nach Sachgruppen. Berlin/New York, 2004, $9-91$.

WOTJAK, B. "Routineformeln im Lernerwörterbuch". In: BARZ, I./ Bergenholtz, H./ Korhonen, J. (eds.): Schreiben, Verstehen, 
Glenk, E. - Fórmulas de rotina: uma porta de entrada para padrões interacionais

Übersetzen, Lernen. Zu ein- und qweisprachigen Wörterbüchern mit Deutsch. Peter Lang, 2005, 371-387. 